\section{DIRECT CONVERSION OF LIGHT HYDROCARBON GASES TO LIQUID FUEL}

Report No, 23

\author{
Quartexly Technical Status Report \\ for \\ Second Quarter F.Y. 1991
}

\begin{abstract}
Project Manager: R. D. Kaplan
\end{abstract}
Principal Investigator: M. J. Foral

Work performed under Contract No. DE-AC22-89PC89866

For

U. S. Department of Energy

Pittsburgh Energy Technology Center

Pittsburgh, Pennsylvania

By

Amoco 0 il Company

Research \& Development Department

Post office Box 3011

Naperville, IL 60566

\section{DISCLAIMER}

This report was prepared as an account of work sponsored by an agency of the United States Government. Neither the United States Government nor any agency thereof, nor any of their employees, rnakes any warranty, express or implied, or assumes any legal liability or responsibility for the accuracy, completeness, or usefulness of any information, apparatus, product, or process disclosed, or represents that its use would not infringe privately owned rights. Reference herein to any specific commercial product, process, or service by trade name, trademark, manufacturer, or otherwise does not necessarily constitute or imply its endorsement, recommendation, or favoring by the United States Government or any agency thereof. The views and opinions of authors expressed herein do not necessarily state or reflect those of the United States Government or any agency thereof.
MASTER

DISTRIBUTION OF THIS DOCUMENT IS UNLIMFTED

Het 1902 
FINAL QUARTERLY PROGRESS REPORT SUBMITTED TO:

1. George Cinquegrane (2 copies)

Contracting officer's Representative

U.S. DOE/PETC

P.O. Box 10940

Pittsburgh, PA 15236

2. Dona G. Sheehan

Contract Specialist

U.S. DOE/PETC

P.O. Box 10940

Pittsburgh, PA 15236

3. Robert M. Hamilton

FE-231, E-155/GTN

U.S. Department of Energy

Washington, DC 20545

4. Gilbert V. McGurl

Program Manager

U.S. DOE/PETC, MS $922-\mathrm{H}$

P.O. Box 10940

Pittsburgh, PA 15236 
ADDITIONAL CIRCULATION FOR DRAFT REPORTS TO:

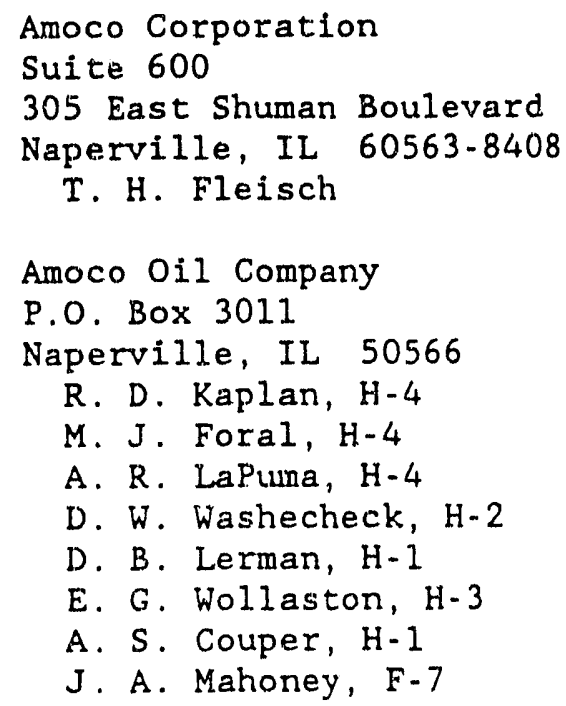


TABLE OF CONTENTS

\section{Page}

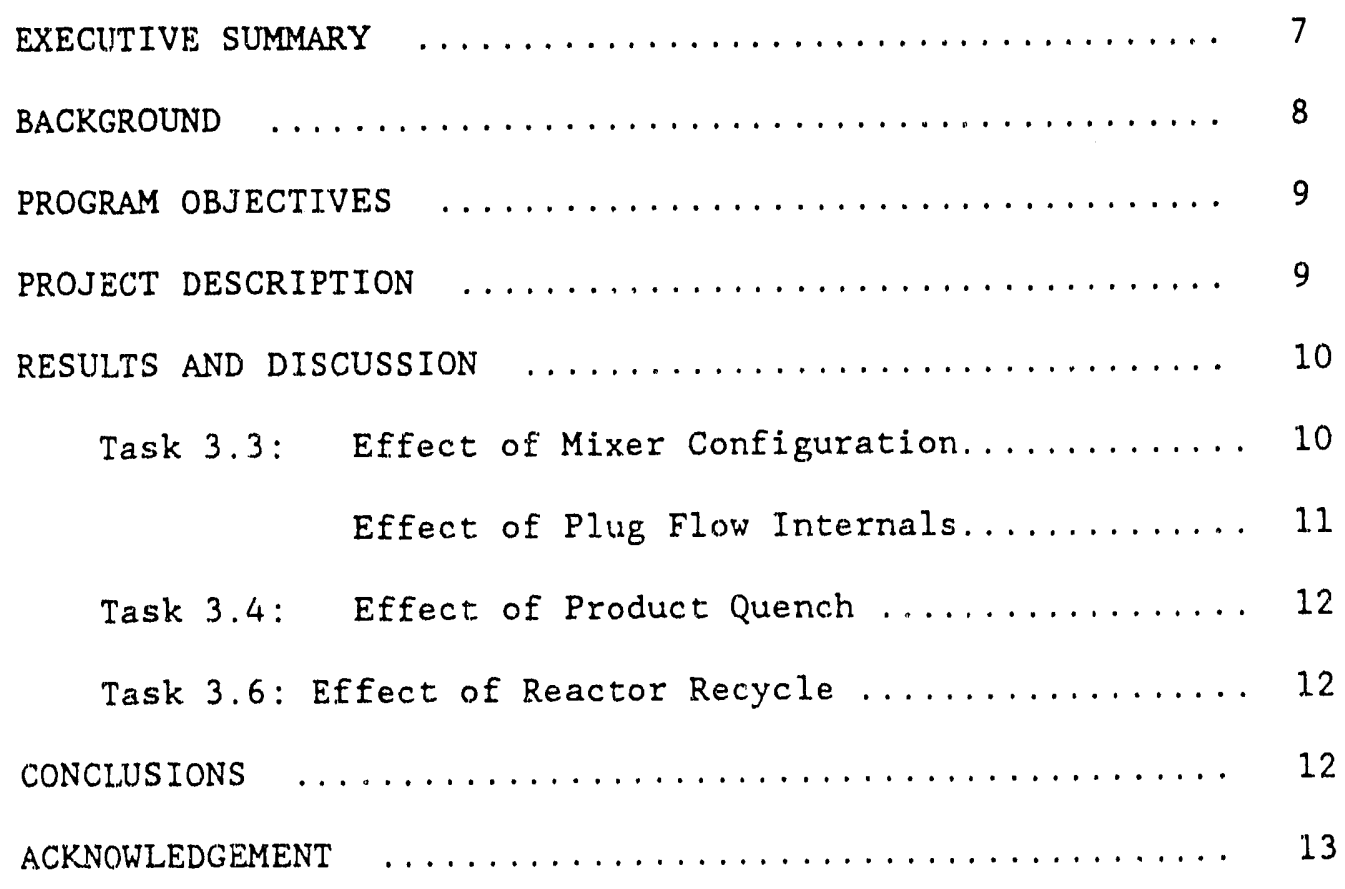




\section{LIST OF FIGURES}

FIGURE 1 Effect of Mixer Type on Methanol Selectivity; Trerd with Oxygen Concentration.

FIGURE 2 Effect of Mixer Type on Methane Conversion; Trend with Oxygen Concentration.

FIGURE 3 Effect of Mixer Type on Hydrocarbon Conversion; Trend with Oxygen Concentration.

FIGURE 4 Effect of Mixer Type on Methanol Yield; Trend with Oxygen Concentration.

FIGURE 5 Effect of Plug Flow Internals on Methanol Selectivity; Trend with Oxygen Concentration.

FIGURE 6 Effect of Plug Flow Internals on Methane Conversion; Trend with Oxygen Concentration.

FIGURE 7 Effect of Plug Flow Internals on Hydrocarbon Conversion; Trend with Oxygen Concentration.

FIGURE 8 Effect of Plug Flow Internals on Methanol Yield; Trend with Oxygen Concentration. 
DISCLAIMER

This report was prepared as an account of work sponsored by the United States Government. Neither the United States nor any agency thereof, nor any of their employees, makes any warranty, expressed or implied, or assumes any legal liability or responsibility for the accuracy, completeness, or usefulness of any information, apparatus, product, or process disclosed, or represents that its use would not infringe privately owned rights. Reference herein to any specific commercial product, process or service by trade name, mark, manufacturer, or otherwise, does not necessarily constitute or imply its endorsement, recommendation, or favoring by the United States Government or any agency thereof. The views and opinions of the authors expressed herein do not necessarily state or reflect those of the United States Government or any agency thereof.

TECHNICAL STATUS

This technical status report is being transmitted in advance of DOE review, and no further dissemination or publication will be made of this report without prior approval of the DOE Project/Program Manager. 


\section{EXECUTIVE SUMMARY}

Amoco Oil Company, under a contract with the United States Department of Energy, is investigating the direct conversion of light hydrocarbon gases to liquid fuels via partial oxidation. This report describes work completed in the sixth quarter of the two-year project. Work continued and progress was made on three tasks during this quarter:

Task 3.3 (Studies of different reactant gas mixing and injection systems): Five different mixer configurations were tested over a variety of oxygen feed concentrations between 1.5 to 12.5 vols. Some effects of mixing were observed, but they do not appear to dramatically improve the overall. economics of this process. At low oxygen concentrations ( 1.5 voli), better mixing resulted in raising methanol selectivity from below 20 mols to over 408 . However, at higher oxygen concentrations (greater than 5 voli) the degree of mixing had little or no effect on methanol selectivity or yield. These higher oxygen concentrations would be required in any economical process because high per-pass conversions are needed. Methane conversion was unaffected by the degree of mixing over the entire range of oxygen concentrations. The best mixing was provided by a $1 / 4$-inch diameter kenics in-line static mixer. The worst mixing was found with a single partially-closed needle valve.

New reactor internals were tested which promoted plug flow of the reactant gases through the reaction zone (i.e. no backmixing). No difference was found between runs with and runs without these plug flow internals. This suggests that jets and eddies caused by injecting the feed gases into the reactor are not limiting methanol selectivity in this system.

Task 3.4 (Studies of different product quench systems): Scoping studies were completed on the effects of product quench. A series of experiments was made both with and without the standard cooling water quench at the reactor: outlet. The results are currently being analyzed and will indicate whether product quenching options should be studied further.

Task 3.6 (Study of the effects of reactor recycle): Cylinder gases have been ordered and received in preparation for recycle simulation experiments. Following the strategy outlined in the Management Plan, we will first simulate the effects of reactor recycle by adding $\mathrm{CO}, \mathrm{CO}_{2}$ and $\mathrm{H}_{2}$ to the base natural gas feed. These components will be added both separately (to determine their fate in the reactor) and in combination (to mimic a mixed feed+recycle stream). Results of these experiments will be reported as they become available. 


\section{BACKGROUND}

Fischer-Tropsch synthesis, gasification processes like Lurgi dry bottom gas, direct coal liquefaction, and remote natural gas all represent sources of substantial quantities of light hydrocarbon gases. Methane is the major and most stable component of all these gases. Steam reforming methane to produce synthesis gas is capital-intensive because it is highly endothermic and requires severe reaction conditions. A process for direct conversion of light gases, especially methane, to methanol, gasoline, or other liquid fuels could be far superior.

Steam reforming is the first stage in traditional commercial methods for the production of liquid fuels. This first step produces syntheses gas:

$$
\mathrm{CH}_{4}+\mathrm{H}_{2} \mathrm{O} \cdots \mathrm{CO}+3 \mathrm{H}_{2} \quad \Delta \mathrm{H}=49.3 \mathrm{kcal}
$$

The synthesis gas is then converted into methanol via a catalytic process.

$$
\mathrm{CO}+2 \mathrm{H}_{2}-\cdots>\mathrm{CH}_{3} \mathrm{OH} \quad \Delta \mathrm{H}=-21.7 \mathrm{kcal}
$$

Reaction 1 produces more hydrogen than required by reaction 2 . The excess can either be utilized elsewhere in the case of a domestic refinery or, in the case of a remote operation, is lost. A third step could be the catalytic condensation of methanol to gasoline.

A more efficient route of converting light hydrocarbons would be to directly form methanol by partial oxidation.

$$
\mathrm{CH}_{4}+\mathrm{O}_{2}-\mathrm{O}_{2}-\Delta \mathrm{CH}_{3} \mathrm{OH} \quad \Delta \mathrm{H}=-30.7 \mathrm{kcal}
$$

Such a process could substantially reduce capital and energy requirements for methanol production. The methanol could be used as a fuel or a fuel blending component, as in the case of $M 80$ fuels ( 80 methanol, 20 gasoline), or else converted into gasoline through well-known processes, such as MTG. A plant based on Reactions 1 and 2 followed by methanol condensation to gasoline has been built and is operating in New Zealand. However, the process is uneconomical if it were not for the New Zealand Governuent support. If a process for the direct conversion of light hydrocarbons to methanol is feasible, thereby elininating the process steps shown by Reactions 1 and 2, then a gas-to-gasoline process could become economically viable.

A proposed process for converting light hydrocarbon gases directly to hydrocarbon liquids, e.g., methanol or formaldehyde, is not new. In 1932 Newitt and Haffner reported the formation of methanol, along with smaller amounts of formaldehyde and formic acid, in the high-pressure oxidation of methane. (1) The reaction was carried out in a static system at $360.393^{\circ} \mathrm{C}$ and $50.150 \mathrm{~atm}$. The maximum methanol selectivfty was ca. 228 ; however, $\mathrm{CH}_{4}$ conversion was only a few percent. More recently, Gesser, Hunter and coworkers have reported methanol selectivities up to 898 and yields of around 7\%. (2) However, other workers have in general beon unable to reproduce these results.

(1) D. M. Newitt, A. E. Haffner, Proc. R. Soc. London, Ser. A, 134, p. 591

(2) H. D. Gesser, N. R. Hunter, Chem. Rev., 15(4), p. 235 (1985); H. D. Gesser, U. S. Patent $4,618,732$, issued $10 / 21 / 86$. 


\section{PROGRAM OBJECTIVES}

The objective of this program is to investigate the direct conversion of light gaseous hydrocarbons, such as those produced during Fischer-Tropsch synthesis or as a product of gasification, to liquid transportation fuels via a partial oxidation process. The process will be tested in an existing pilot plant to obtain credible mass balances. Specific objectives to be met include determination of optimal process conditions, investigation of various processing options (e.g. feed injection, product quench, and recycle systems), and evaluation of an enhanced yield thermal/catalytic system. Economic evaluation of the various options will be performed as experimental data become available.

\section{PROJECT DESCRIPTION}

The project is of two years' duration and contains three major tasks. The third task (Pilot Plant Experiments) contains seven subtasks, corresponding to the project objectives outlined above. The tasks and subtasks foreseen when the project began are described below.

Task 1.-.Project Management Plan: A plan will be prepared describing the work to be done, milestones, and mampower requirements and costs.

Task 2.-.Pilot Plant Modification: An existing pilot plant dedicated to investigation of light hydrocarbon conversion will. be modified to provide it with the capability to handle the processes and conditions of this program. These modifications will include construction of a new reactor, construction and installation of reactant injection and product quench systems, and, possibly, addition of a product recycle loop to the unit.

Task 3,1.--Comparison of Preliminary Data With Los Alamos Model: We will determine if the kinetic model developed by Los Alamos National Laboratory can be used to guide our experimental effort. Results from this task will be carefully analyzed and will determine the direction of the subsequent experimental program. This is a major decision point in the project.

Task 3.2.--Pressure/Temperature/Reaction Time Effects: The methane conversion data base will be extended over the following range of conditions:

$\begin{array}{ll}\text { Temperature: } & 600 \text { to } 1100 \mathrm{~F} \\ \text { Pressure: } & 200 \text { to } 1300 \mathrm{psig} \\ \text { Reaction Time: } & 3 \text { to } 90 \text { seconds }\end{array}$

These experiments will be guided by the results of Task 3.1 to those process regimes which appear most promising.

Task 3.3.-.Study of Different Injection Systems: Different schemes for introducing and mixing reactants before or within the reactor will be evaluated theoretically and/or experimentally. The goal will be to maximize methanol yield. 
Task 3.4.-. Study of Different Quench Systems: The efficacy of different product cooling techniques will be investigated to determine the effect of quenching on product composition and methanol yield. Both gas and liquid quench options will be investigated.

Task 3.5.--Effect of Reactor Geometry: The effect of reactor geometry, particularly aspect (i.e. length/diameter) ratio, will be investigated to determine mass transfer and mixing effects on product composition and methanol yield.

Task 3.6.-.Effect of Reactor Recycle: The effect of recycling unreacted hydrocarbons to the reactor inlet will be evaluated first by appropriately blending the feed stream to simulate reactor recycle. If these results are promising relative to methanol production, a recycle compressor and recycle line will be added to the pilot plant for more detailed tests.

Task 3.7.-. Enhanced-Yield Catalyst Study: An attempt will be made to develop a combined thermal/catalytic process in which byproduct carbon monoxide and hydrogen from the thermal process is converted to methanol over a heterogeneous catalyst. Such a combined process may provide higher methanol yields than the thermal process alone.

Reporting will be done periodically throughout the duration of the project according to DOE guidelines.

\section{RESULTS AND DISCUSSION}

During this quarter, work was completed on Task 3.3 (Study of Feed Injection systems). On the basis of discussions wi:h Professor Gesser at the University of Manitoba, these studies cuncentrated on the effects of mixing the feed hydrocarbon and oxygen streans to various degrees. Five different mixer configurations were studied and their effects on methanol yield and methane conversion determined. In addition, we tested new reactor internals which helped ensure plug flow through the reaction zone. The results of these studies are discussed in detail below.

\section{Task 3.3: Effect of Different Mixer Configurations}

Experiments were made to test the efficacy of different mixer configurations for increasing methane conversion or methanol yield. Some effects of mixing were observed. These effects are significant, but do not dramatically improve the overall economics of the process. Five different mixer configurations have been tested over a variety of oxygen feed concentrations from 1.5 to 12.5 volis:

1) a packed bed mixer consisting of $1 / 8$-inch ceramic balls in a $1 / 2$-inch diameter tube (this is the original mixer configuration),

2) a partially closed needle valve (similar to the mixer used by Professor Gesser at the University of Manitoba),

3) a series of two partially closed needle valves,

4) a 1/2-inch diameter static mixer manufactured by Kenics containing 24 fixed mixing elements, and 
5) a 1/4-inch diameter Kenics static mixer containing 27 mixing elements.

Based on previous process variable studies and the desire to maximize methanol yield, the pressure was held at 1300 psig and the residence time at 55 seconds in all runs. The reactor was $30 \mathrm{~mm}$ in diameter.

Figures 1-4 show the effects of mixer type and oxygen concentration on methanol selectivity, methane conversion, hydrocarbon conversion and methanol yield, respectively. At $\mathrm{O}_{2}$ concentrations above about 5 vols, mixer type had little effect on methanol selectivity (Figure 1). At lower concentrations, however, some differences were apparent. Mixers (1), (3) and (4) all gave similar results, with methanol selectivity peaking at around 35 molo (at 6 voli $\mathrm{O}_{2}$ ) and falling to around $23 \mathrm{~mol}$ at lower oxygen levels ( 1.5 voli). The single needle valve (mixer (2)) gave slightly lower selectivities, peaking at axound $30 \mathrm{~mol}$ and falling to 15 molo at lower oxygen levels. The $1 / 4$-inch Kenics mixer (mixer (5)) performed the best, showing a monotonic increase in methanol selectivity with decreasing oxygen level. The maximun methanol selectivity with this mixer was 40 molo at an oxygen level of 1.5 voli. Figures 2 and 3 show that methane and hydrocarbon conversions were not significantly affected by mixer type over the entire range of oxygen concentrations.

With every mixer type the maximum methanol yield was around 4.5 molo (Figure 4 ), but there were differences in the oxygen level at which this maximum occurred. With the 1/4-inch Kenics mixer the maximum yield occurred at lower oxygen levels ( $1.5-5$ voli), with the single partially-closed needle valve the maximum was near 8-10 voli $\mathrm{O}_{2}$, and with all other mixers the maximum occurred between 6-8 voli $\mathrm{O}_{2}$. These results indicate that mixer configuration has some effect on the performance of the system. However, since the maximum methanol yield is not significantly affected, it does not appear that improved mixing will lead to any significant improvement in process economics.

\section{Task 3.3: Effect of Plug Flow Reactor Internals}

A series of experiments was run to test the efficacy of reactor internals designed to promote plug flow in the reaction zone. Since the desired product in this system (methanol) reacts more easily with oxygen than the methane faed, any backmixing in the reaction zone will serve to reduce both methanol selectivity and overall yield. To help promote plug flow in the reaction zone, a quartz fritted disk was placed at the top of the reaction (heated) zone. This prevented any eddies or jets that may be created at the feed inlet ports from entering the reaction zone. A series of runs was then made at various oxygen concentrations and pressures.

Figures 5-8 show the effects of these plug-flow internals on methanol selectivity, methane conversion, hydrocarbon conversion, and methanol yield, respectively as a function of oxygen concentration. The runs with the fritted disk internals are compared with runs at similar conditions without the fritted disk (i.e. open tube runs).

All of the figures show that there is no significant effect of the fritted disk on either selectivity or conversion. Figure 5 indicates that methanol selectivity increases monotonically with decreasing oxygen concentration both with and without the fritted aisk internals. Differences between the two series of runs are well within the experimental uncertainty. Figures 6 and 7 


\section{Figure 1}

Effect of Mixer Type on Methanol Selectivity

Trend With $\mathrm{O} 2$ Concentration

Methanol Selectivity (\%)

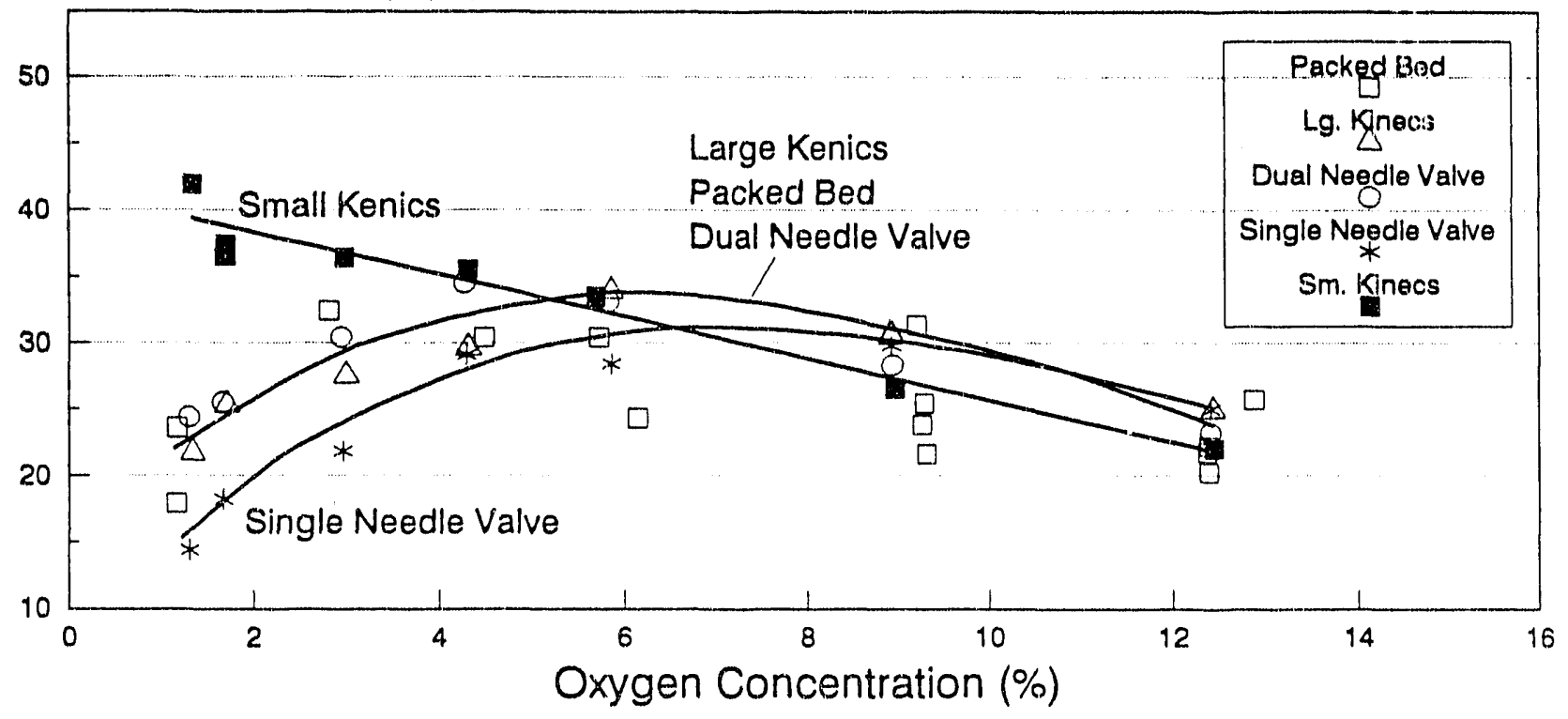

Figure 2

Effect of Mixer Type on Methane Conversion

Trend With 02 Concentration

Methane Conversion (\%)

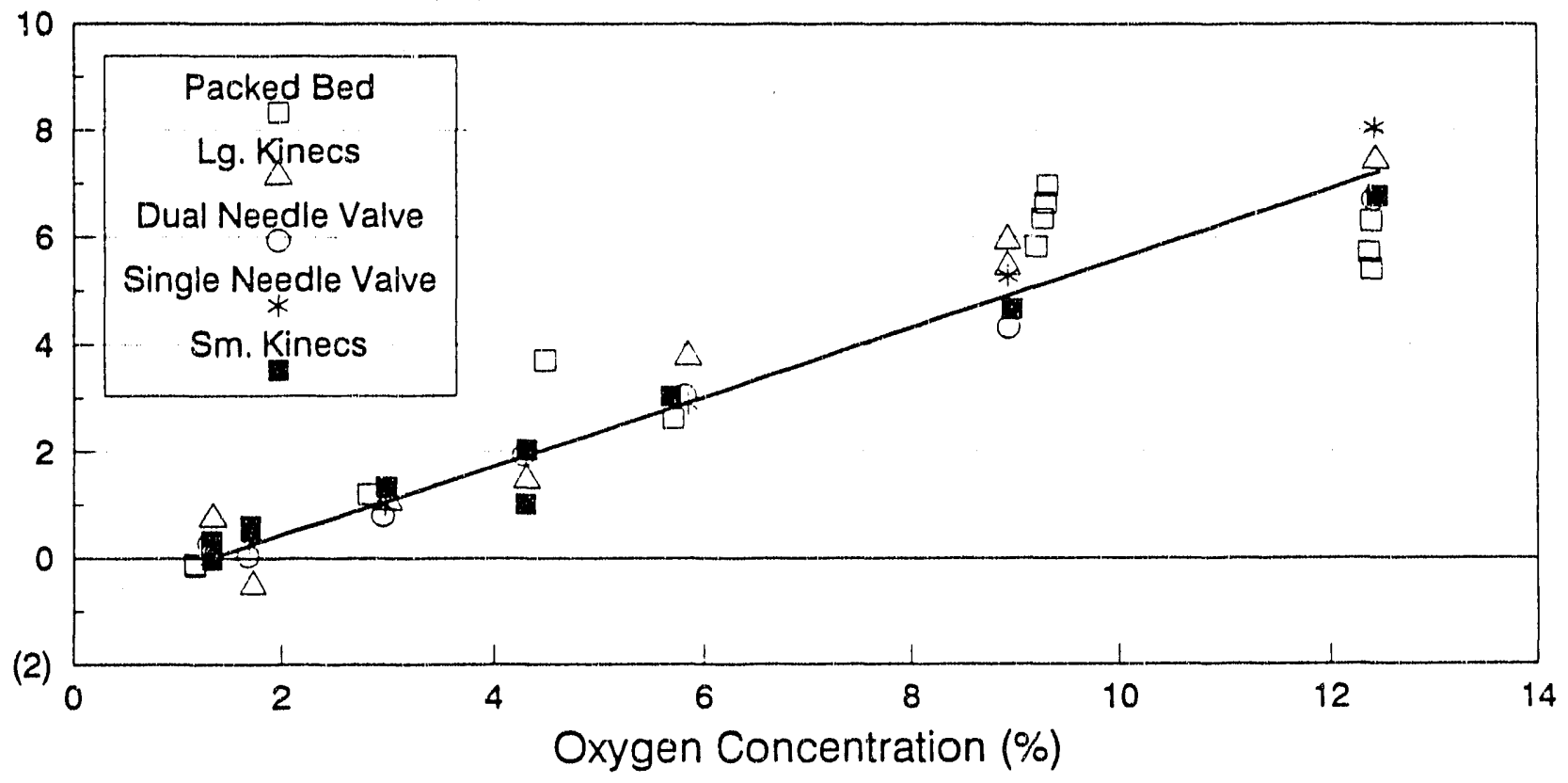




\section{Figure 3}

Effent of Mixer Type on Hydrocarbon Conversion

Trend With $\mathrm{O} 2$ Concentration

Hydrocarbon Conversion (\%)

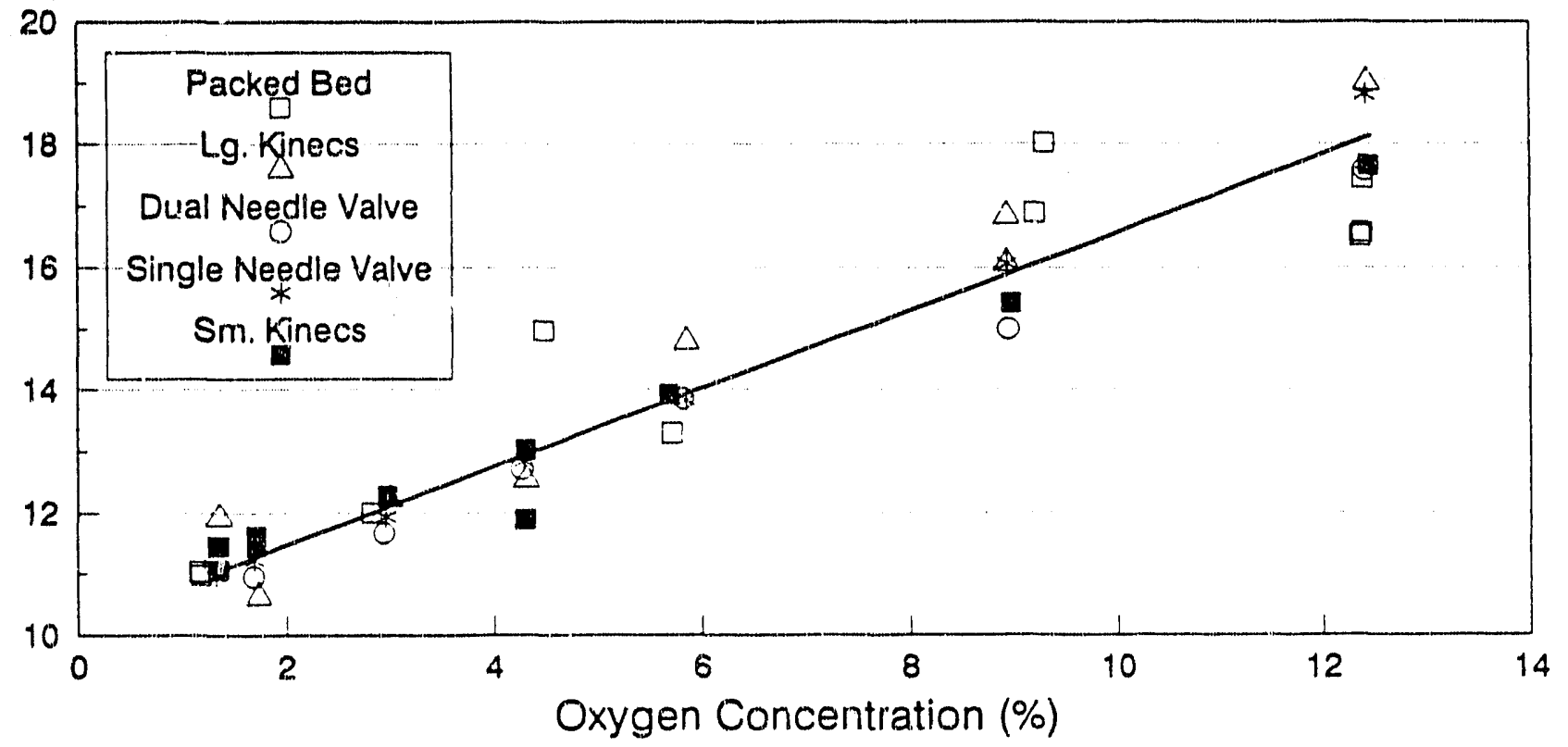

Figure 4

Effect of Mixer Type on Methanol Yield

Trend With $\mathrm{O} 2$ Concentration

Methanol Yield (\%)

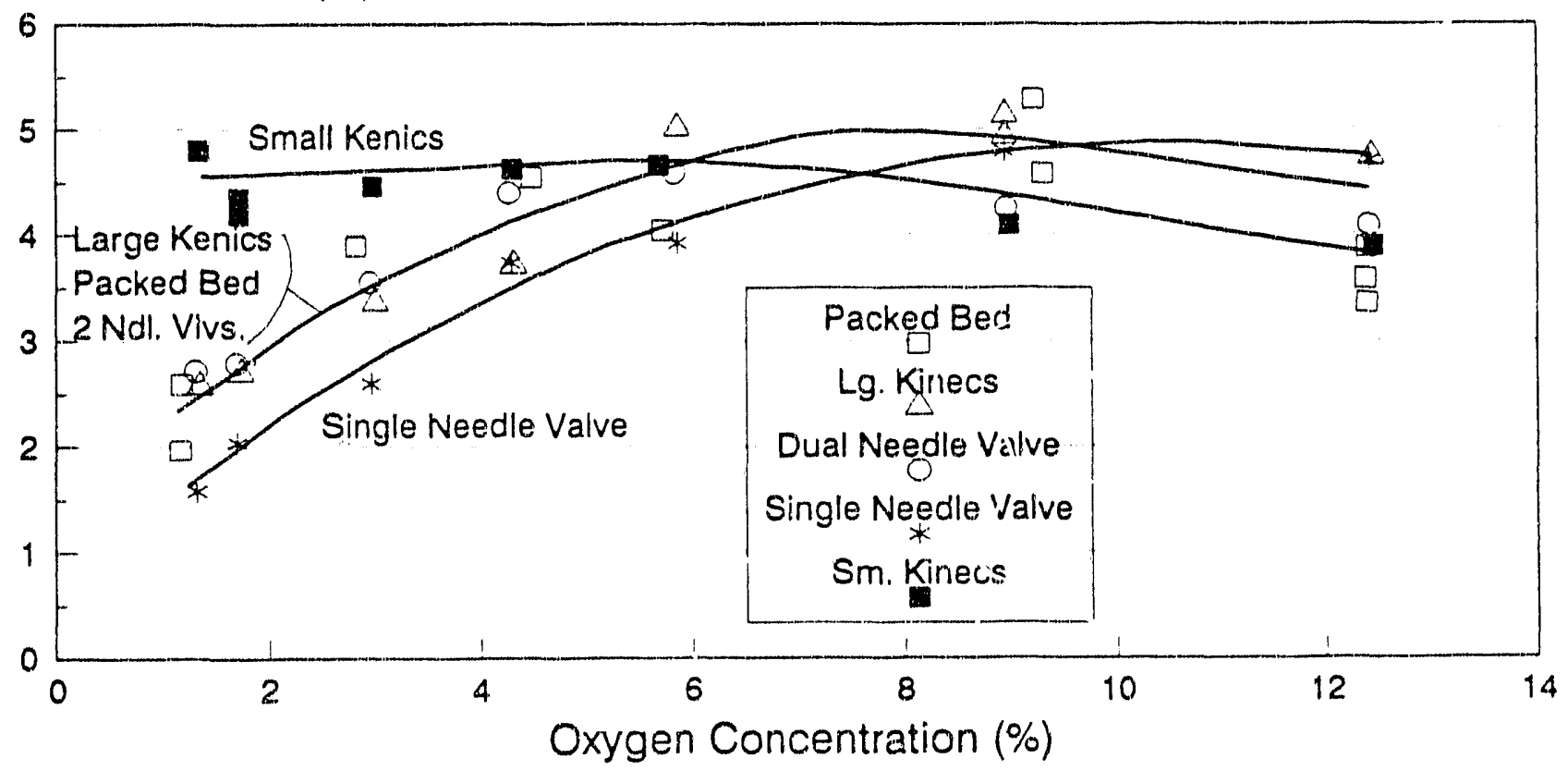




\section{FIGURE 5}

Effect of Fritted Disk on MeOH Selectivity

$T=800 \mathrm{~F} ; P=1300 \mathrm{psig} ;$ Res. Time $=40 \mathrm{Sec}$.

Methanol Selectivity (mol\%)

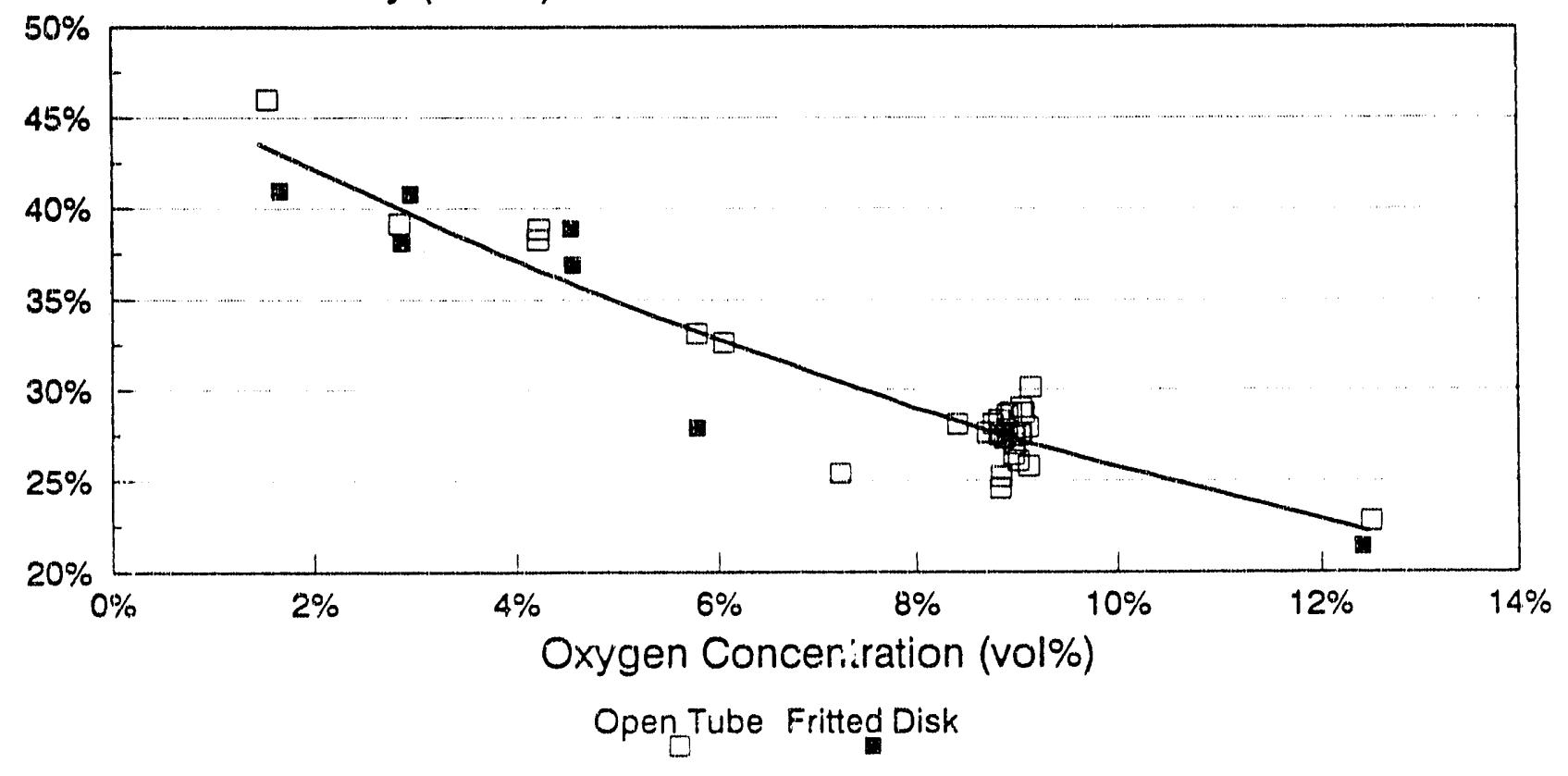

FIGURE 6

Effect of Fritted Disk on Methane Conversion

$T=800 \mathrm{~F} ; P=1300$ psig; Res. Time $=40 \mathrm{Sec}$.

Methane Conversion (mol\%)

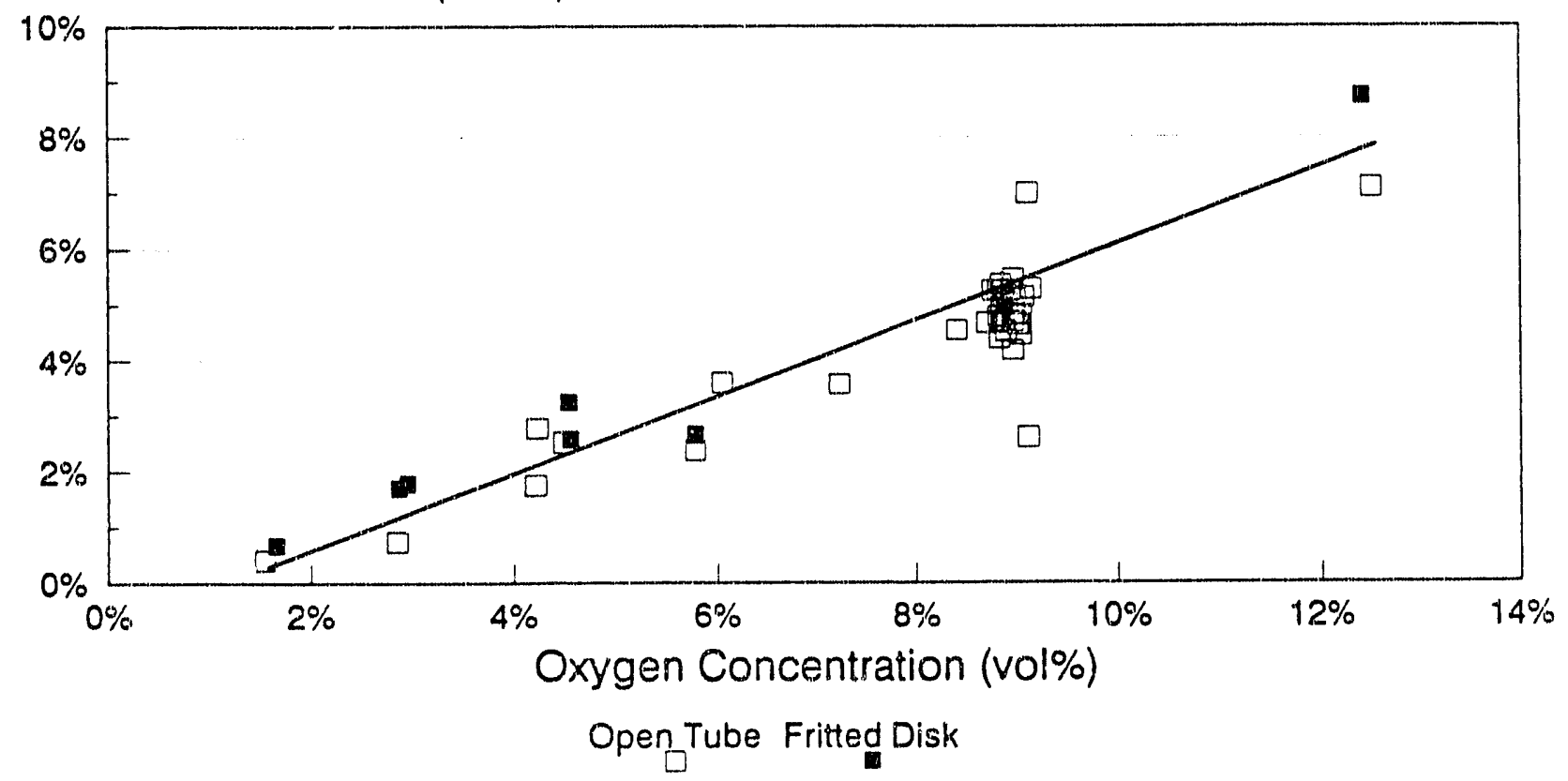




\section{FIGURE 7}

Effect of Fritted Disk on Hydrocarbon Conversion

$T=800 \mathrm{~F} ; P=1300$ psig; Res. Time $=40 \mathrm{Sec}$.

Hydrocarbon Conversion (mol\%)

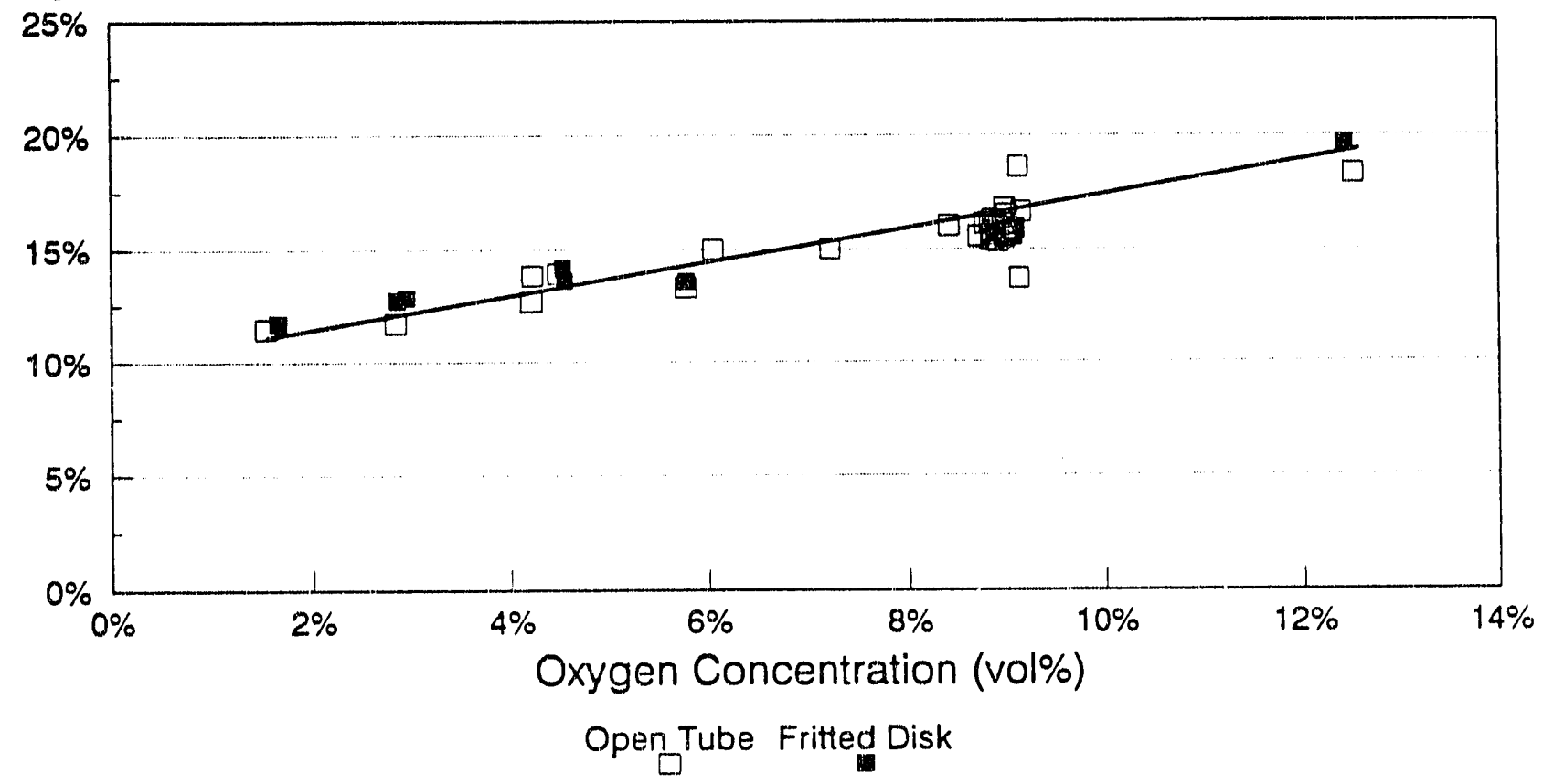

FIGURE 8

Effect of Fritted Disk on Methanol Yield

$T=800 \mathrm{~F} ; P=1300$ psig; Res. Time $=40 \mathrm{Sec}$.

Methanol Yield (mol\%)

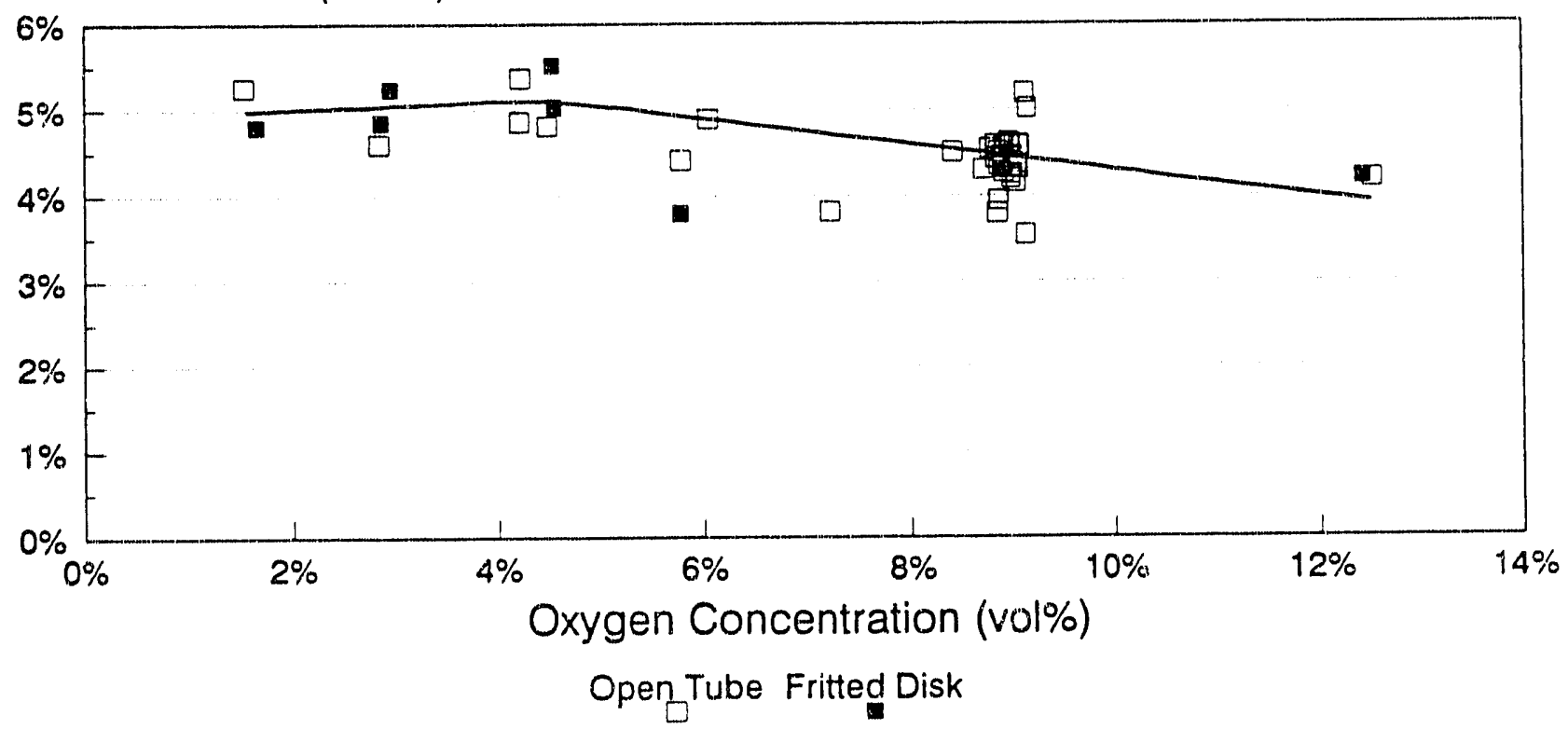


show that conversion is not affected by the presence of the fritted disk internals. Figure 8 indicates that with both configurations the maximum methanol yield is around 5 molo. This maximum occurs at oxygen concentrations below 5 voli. A series of runs at pressures between 500 and 1300 psig also showed that the fritted disk internals had no effect on the reaction.

These results indicate that the observed selectivities and conversions are not being limited by backmixing caused by eddies or jets from the feed injection ports. We cannot, however, conclude from this that backmixing in the reactor is not a problem. Due to the high temperatures and relatively long residence times in the vertical reactor, the existence of thermal convection currents cannot be ruled out. Such thermal convection in the reaction zone would not. be affected by the fritted disk at the very top of the reactor. The fact that the reactor is top-fed would magnify the dfimental effects of any convection currents because the methanol-rich convection current would be carried up into the more oxygen-rich zones where it could be further oxidized.

A series of experiments is currently underway in which a reactor packed with quartz beads is being studied. These experiments are part of a study of reactor geometry (Task 3.5) in which surface-to-volume ratio is decoupled from reactor diameter. However, information on convection effects might also be inferred from these experiments, since the packed bed will disrupt thermal convection currents.

Task 3.4: Study of Different Quench Systems

Scoping studies have been completed on the effects of product quench. The current pilot plant design utilizes an external cooling water quench located just downstream of the heated reaction zone. Experiments were run both with and without this cooling water quench system operating. The results are being analyzed. Since relatively long residence times (20-60 seconds) were found to be optimal, it is not expected that rapid querching of the products will have any significant effect on selectivity or conversion. The results from these scoping studies will indicate whether other product quenching options should be studied.

Task 3.6: Effect of Reactor Recycle:

Cylinder gases have been ordered and received in preparation for the recycle simulation experiments. Following the strategy outlined in the Management $\mathrm{Plan}$, we will first simulate the effects of reactor recycle by adding $\mathrm{CO}, \mathrm{CO}_{2}$ and $\mathrm{H}_{2}$ to the base natural gas feed. These components will be added both separately (to determine their fate in the reactor) and in combination (to mimic a mixed feed+recycle stream). Results of these experiments will be reported as they become available.

\section{CONCLUSIONS}

The above results indicate that while improved mixing of the reactant gases increases methanol selectivity at low oxygen concentrations (below 5 voli), there is little or no effect of feed mixing on either methanol yield or selectivity at higher oxygen levels. The maximum methanol yield in each case is between 4.5 and 5.0 molis, far below that required for economic viability (ca. 14 molo yield). The oxygen level at which this maximum occurs is 
influenced by the extent of mixing; better mixing causes the maximum methanol yield to occur at lower oxygen levels. The best mixer tested as a $1 / 4$-inch Kenics in-line static mixer with 27 fixed mixing elements. With this mixer the maximum methanol selectivity was 40 molo at 1.5 voli oxygen, and the maximum methanol yield was 4.8 molo at between 4 and 6 volis oxygen. The poorest mixer tested was a single partially-closed needle valve. With this mixer the maximum methanol selectivity was $30 \mathrm{~mol}$ a and the maximum methanol yield was 4.8 molo, both occurring at between 8 and 10 voli oxygen.

Methanol selectivity and yield in this system are apparently not being limited by backmixing caused by jets or eddies from the reactant injection ports. There is no effect observed when these jets or eddies are excluded through the use of internals which enhance plug-flow. Conclusions cannot be drawn, however, on whether thermal convective mixing is limiting the methanol yield in this system. Experiments are under way to assess this possibility.

\section{ACKNOWLEDGEMENT}

This work was supported by the United States Department of Energy inder Contract DE-AC22-89PC89866. 
This report was prepared by the organization(s) named below as an account of work sponsored by the United States Department of Energy (DOE). Neither DOE, members of DOE, the organization(s) named below, nor any person acting on behalf of any of them: (a) makes any warranty, express or implied, with respect to the use of any information, apparatus, method, or process disclosed in this report or that such use may not infringe privately owned rights; or (b) assumes any liabilities with respect to the use of, or for damages resulting from the use of, any information, apparatus, method, or process disclosed in this report.

Prepared by

Amoco Oil Company (Amoco Corporation)

Naperville, Illinois

$/ M J F / j m b / 9107$ 


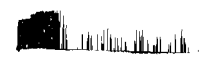

s.
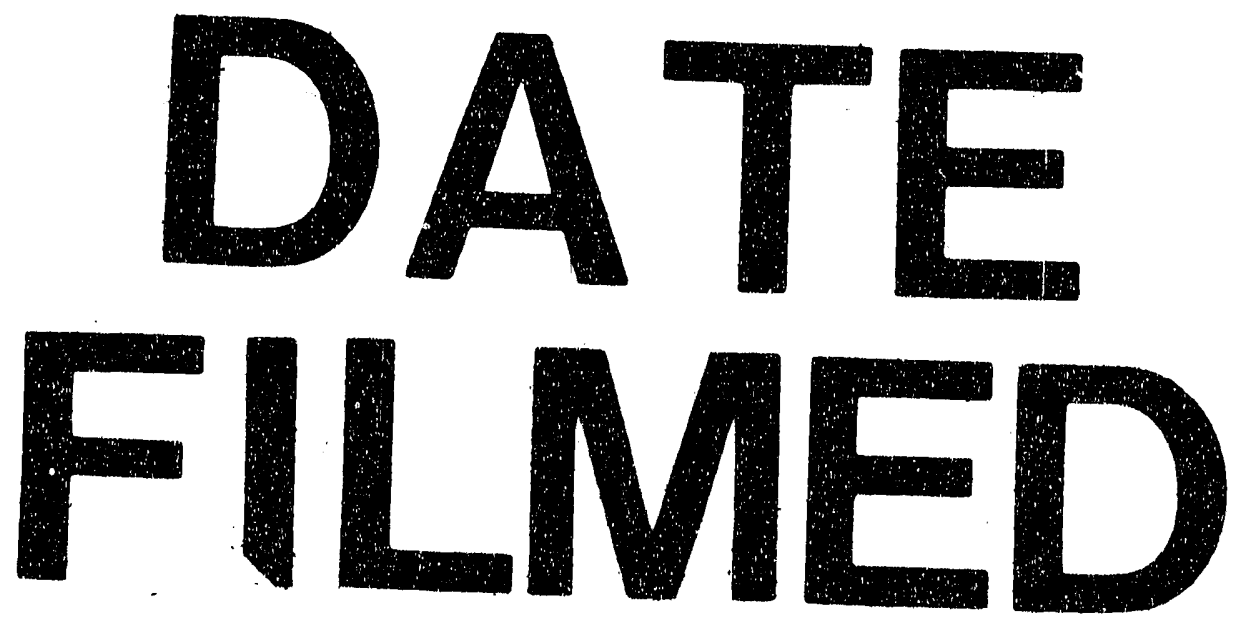

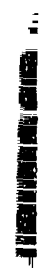

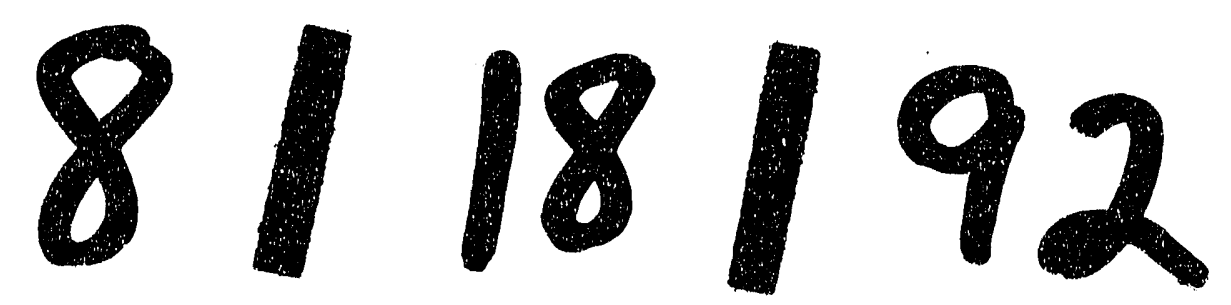


